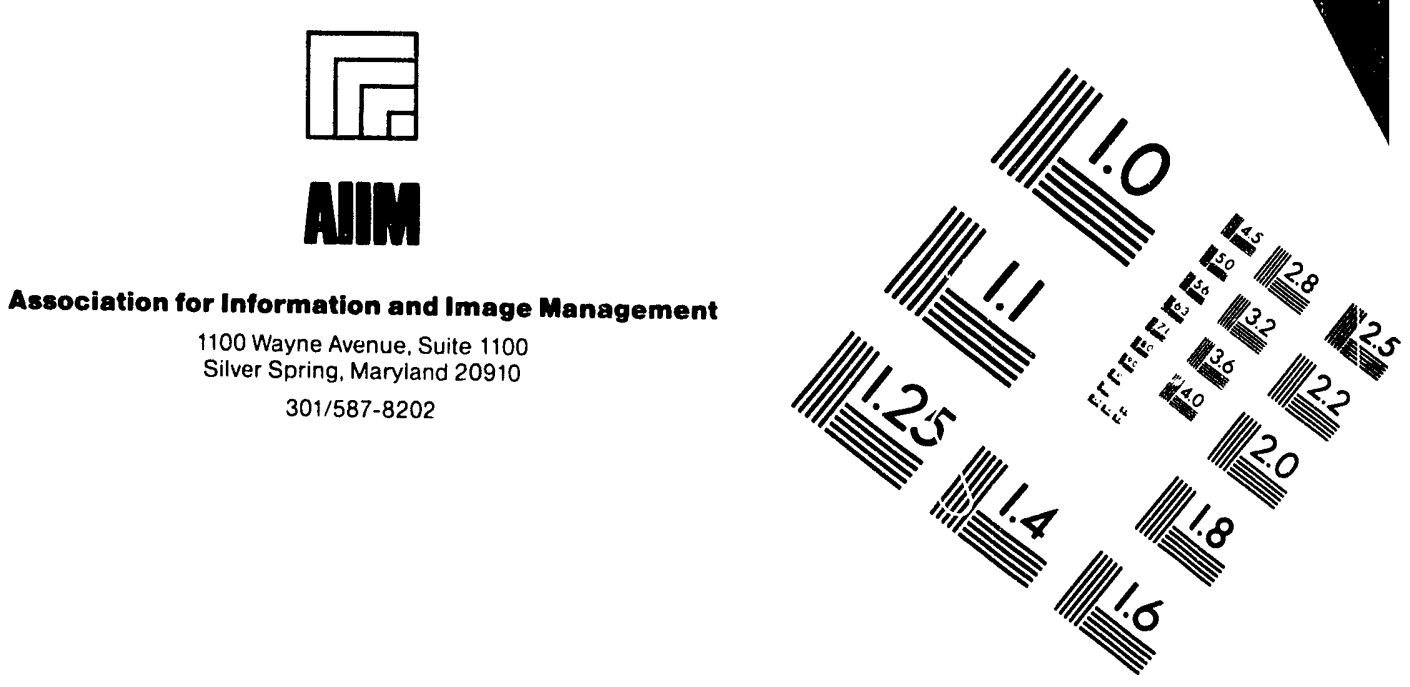

\title{
Centimeter
}

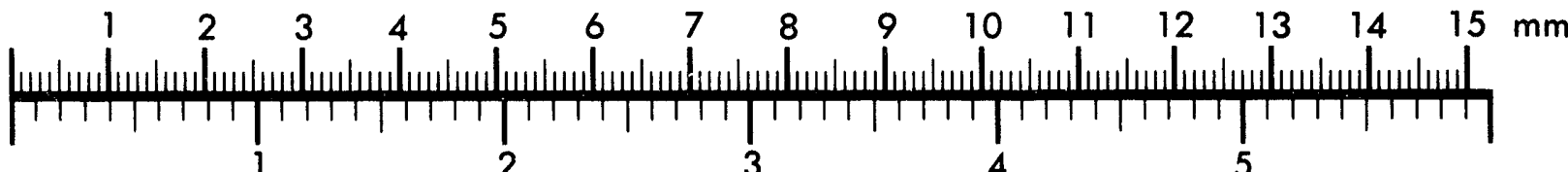

Inches
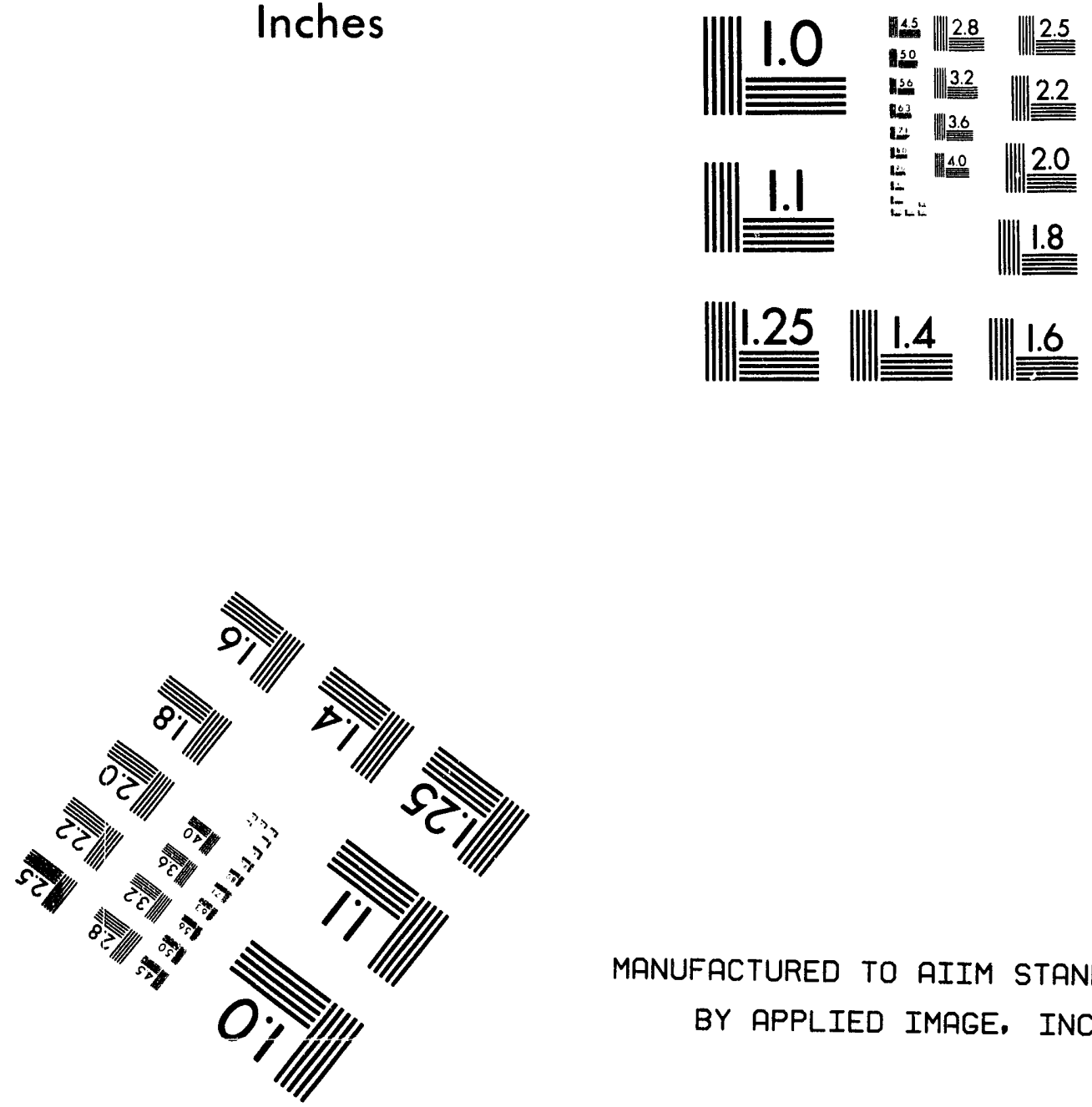

MANUFACTURED TO AIIM STANDARDS

BY APPLIED IMAGE, INC.

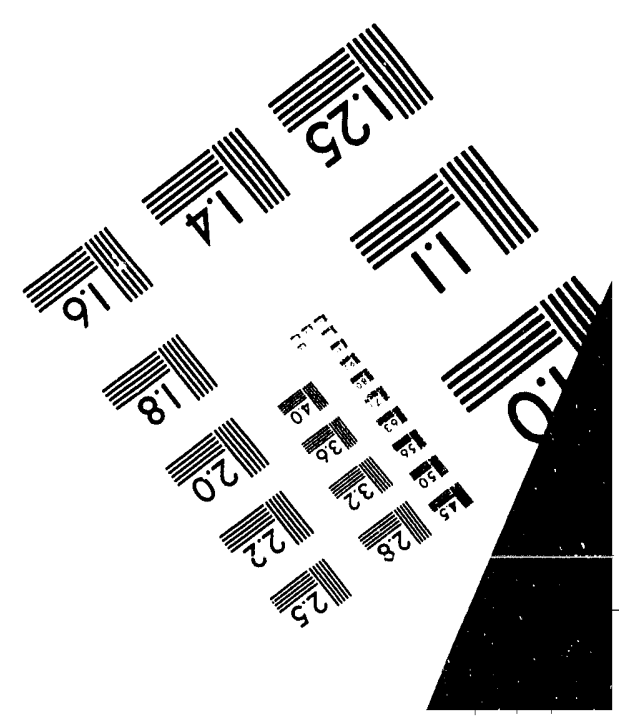



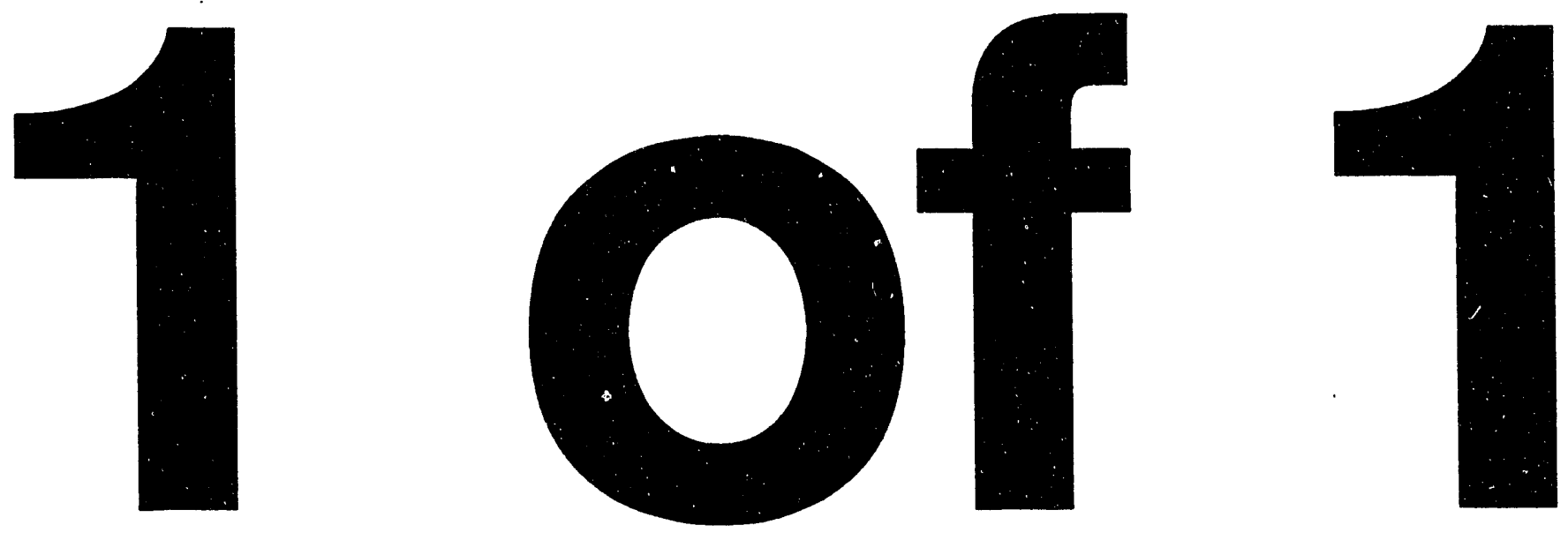


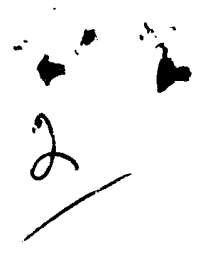

TECHNICAL REPORT

March 1, 1993 through May 31, 1993

\section{Project Title: CLEAN, PREMIUM-QUALITY CHARS: DEMINERALIZED AND CARBON ENRICHED}

DE-FC22-92PC 92521

Principal Investigator:

Other Investigators:
Gerard V. Smith

Molecular Science Program

Southern Illinois University

Carbondale, IL 62901

(618) 453-7319

Vivak M. Mal.hotra

Department of Physics

Southern Illinois University

Carbondale, IL 62901

Tomasz Wiltowski

Molecular Science Program

Southern Illinois University

Carbondale, IL 62901

Eugeniusz Myszka

Molecular Science Program

Southern Illinois University

Carbondale, IL 62901

Dan Banerjee, ICCI

Project Manager:

ABSTRACT

The overall objective of this two-year project is to evaluate methods of preparing demineralized and carbon enriched chars from Illinois Basin coals. There are two processing steps: physical cleaning of the coal and devolatilization under different environments to form chars. Two differents techniques were used, in-situ Diffuse Reflectance FTIR measurements and BTU measurements. Experiments were performed with coals IBC-101, 102, and 104 as received and after cleaning. DR-FTIR spectrums helped to explain the possible existing chemical bonds in the coal structure as well as their changes during drying and mild pyrolysis. Drying coal causes hydrogen bonds between water and coal to be broken. Liquids produced above $500^{\circ} \mathrm{C}$ are much higher in aromatic content, thus, effectively reducing the concentration of aliphatic groups in the overall liquid yield. BTU values of coals after methane treatment are higher than after helium treatment. 


\section{EXECUTIVE SUMMARY}

The goal of this project is to develop a process that can produce a clean, desulfurized, premium-quality char from Illinois basin coals. This goal is achieved by utilizing the effective properties of smectites in combination with methane to manipulate char yields. The general objectives are to determine the optimum particle size of the coal for this process, to find the most reactive type of smectite and the method of its dispersion on the coal surface, to find the best conditions of removing sulfur from the char under the combination of methane/oxygen or helium/oxygen, and, finally, to identify the conditions for rejection of smectites from char by the gravitational separation technique.

Experiments were performed with IBC-101, IBC-102, and IBC104 coals as received and after cleaning. Two different analytical techniques were used, in-situ Diffuse Reflectance-Fourier Transform Infrared measurements (ISDR-FTIR), and BTU measurements.

In-situ Diffuse Reflectance-FTIR measurements showed that on drying the coals undergo structural changes. The maximum yields of liquids occurs at $500^{\circ} \mathrm{C}$ for IBC-101 coal, while similar data for IBC-102 coal indicate that maximum liquids are produced at $550^{\circ} \mathrm{C}$. Other experiments show that above $550^{\circ} \mathrm{C}$ liquids from IBC-102 coal are higher in aromatic content, thus effectively reducing the concentration of aliphatic type products in the overal liquids. As pyrolysis temperature is increased, the aliphatic-to-aromatic ratio first increases reaching a maximum at $300^{\circ} \mathrm{C}$ and then progressively decreases. Long-chain aliphatic hydrocarbons crack into small fragments at $200^{\circ} \mathrm{C}<\mathrm{T}<350^{\circ} \mathrm{C}$ and devolatilize.

Clean coals always have larger BTU values than coals "as received" coals because removing the mineral matter, which has zero BTU value, increases BTU values of remaining carbonaceous material (per weight unit). Generally, pyrolysis of coals at $700^{\circ} \mathrm{C}$ decreases their BTU values due to removal of volatile material from the coal matrix. However, BTU values of coals after $\mathrm{CH}_{4}$ treatment is higher than after $\mathrm{He}$ treatment, which confirms that methane decomposes and deposits carbon at the char surface.

\section{DISCLAIMER}

This report was prepared as an account of work sponsored by an agency of the United States Government. Neither the United States Government nor any agency thereof, nor any of their employees, makes any warranty, express or implied, or assumes any legal liability or responsibility for the accuracy, completeness, or usefulness of any information, apparatus, product, or process disclosed, or represents that its use would not infringe privately owned rights. Reference herein to any specific commercial product, process, or service by trade name, trademari, manufacturer, or otherwise does not necessarily constitute or imply its endorsement, recommendation, or favoring by the United States Government or any agency thereof. The views and opinions of authors expressed herein do not necessarily state or reflect those of the United States Government or any agency thereof. 


\section{OBJECTIVES}

The goal of this two years project is to develop a benchscale procedure to produce clean, desulfurized, premiumquality chars from the Illinois basin coals. This goal is achieved by utilizing the effective properties of smectites in combination with methane to manipulate the char yields. The major objectives are:

a. to determine the optimum water-ground particle size for the maximum reduction of pyrite and minerals by the selective-bitumen agglomeration process,

b. to evaluate the type of smectite and its interlamellar cation which enhances the premium-quality char yields,

c. to find the mode of dispersion of smectites in clean coal which retards the agglomeration of char during mild gasification,

d. to probe the conditions that maximize the desulfurized clean-char yields under a combination of methane/oxygen or helium/oxygen,

e. to characterize and accomplish a material balance of chars, liquids, and gases produced during mild gasification,

f. to identify the conditions, which reject dehydrated smectites from char by the gravitational separation technique, and

g. to determine the optimum seeding of chars with polymerized maltene for flammability and transportation

\section{INTRODUCTION AND BACKGROUND}

Coal carbonization is a well-established technology ${ }^{1,2}$, next only to the combustion utilization of coal, but its economic viability has considerably eroded due to competition from other relatively cheap energy sources. Therefore, recent emphasis in carbonization process development has been on using mild gasification and gasifications conditions to recover liquids and gases, which can act as chemical feedstock ${ }^{1-16}$. Far less effort ${ }^{17-21}$ has been devoted to developing technology for producing enhanced yields of char or premiumquality char from coals. To make the mild coal gasification process commercially successful, production and utilization of clean, premium-quality chars are mandatory.

The high inorganic and organic sulfur content of Illinois 
bituminous coals in general and the high mineral content of some Illinois coals present significant hurdles for their effective, economical, and environmentally-acceptable utilization. This is especially true for the mild gasification of Illinois coals since it results in by-products, both liquids and solids, which have an environmentally unacceptable sulfur content. Additionally, the high ash content (for example, $10.4 \%$ in IBC-101 coal or $38.3 \%$ in IBC-104 coal) of Illinois coals may actually dilute the coal to such an extent that the coking properties of the coal are markedly diminished. Also, chars rich in minerals foul catalytic promoters via catalytic-material-mineral reactions in the gasification process ${ }^{2}$. Therefore, prior to subjecting Illinois coals to the mild gasification process to produce chars and liquids, they must be physically cleaned to reduce mineral and pyrite content.

Removal of pyrite and other minerals from Illinois bituminous coals is a vexing problem to coal preparation engineers. Most advanced, mechanical coal cleaning processes take advantage of the differences in surface properties of minerals and organic coal when removing pyrite and other minerals. These processes (e.g., aggregate flotation, aglofloat process, static tube flotation, selective-froth flotation, microbubble flotation, air-sparked hydrocyclone, ultrasonically enhanced flotation, reverse coal-pyrite flotation, and the Otisca process) add surfactants, frothers, and surface-active polymers to separate minerals from coals ${ }^{3}, 24$. Unfortunately, the mechanical-coal cleaning processes have had only 1 imited success ${ }^{24}$ in rejecting pyrite from bituminous coal. In the aforementioned coalcleaning processes the floatability of organic coal relative to minerals is selectively enhanced by external additives which adsorb on the surfaces of cleanea coal particles and have serious repercussion during mild gasification.

The thermal decomposition of coal is a complex sequence of events, which can be described in terms of several physicochemical changes, e.g., it has been suggested ${ }^{1 j}$ that some tar formation appears at about $350^{\circ} \mathrm{C}$ from volatilization of low molecular weight coal constituents, and this event is followed by major tar yields at $400^{\circ}-450^{\circ} \mathrm{C}$. It is also known ${ }^{1}$ that certain coals become soft and fluid with the release of liquids and gases when heated to $400^{\circ}-600^{\circ} \mathrm{C}$, where thermal depolymerization occurs. During the mild gasification process, surfactants and/or polymer additives present on the surface of clean coal will act as effective sites for cross-linking (agglomerating) coal particles and incorporating deleterious additives, which may further retard effective utilization of the chars. Consequently, the cleaning process employed to produce clean coal feedstock for mild gasification must not include additives which can retard mass transport. 
To remove pyrite and other minerals coal must be ground with water prior to the cleaning process ${ }^{25}$. This wet grinding results in the formation of hydrated-sulfate species on pyrite, irrespective of their location, and inhibits coal oxidation, which further attenuates cross-linking (agglomeration) of coal under mild gasification ${ }^{13}$.

Chars produced from clean coal can be upgraded by treatment with methane, which desulfurizes char and deposits carbon on its surface. Desulfurization occurs chiefly from the interaction of methane with pyrite ${ }^{36}$ :

$$
\mathrm{CH}_{4}+2 \mathrm{FeS}_{2}-\cdots->\mathrm{CS}_{2}+2 \mathrm{Fe}^{\circ}+2 \mathrm{H}_{2} \mathrm{~S}
$$

However, considering the fairly ready transfer of sulfur between inorganic (mineral) and organic phases ${ }^{37}$, desulfurization of organic phases likely occurs. In view of our previous study we believe that clean coal obtained from the selective bitumen agglomeration process will experience further reduction of the sulfur when subjected to mild gasification under the mixture of $\mathrm{CH}_{4}$ with $2 \mathrm{o}_{2}$. This combination of methane and oxygen gas not only will reduce the sulfur content of the remaining pyrite but also will eliminate organically bound sulfur.

Deposition of carbon from methane decomposition on chars may occur in an amorphous form with extremely high surface area and in a filamentous form with high mechanical strength. These filaments grow from small crystallites of metals, 38 , 39, which can be produced in the char.

Carbon may be deposited from methane by the action of high temperatures and/or metal catalysts ${ }^{40}$ as well as carbon. 41,42 High temperature deposition of carbon leads to either amorphous (soot-like) 41,42 or graphitic carbon ${ }^{40}$ depending on the presence and kind of surface available. These carbons, especially the amorphous carbons, have very high surface areas. On the other hand, filamentous carbons have moderate surface areas but high mechanical strength. A modification of carbon filaments, "cauliflower-like" graphitic structures ${ }^{39}$, exhibit moderately high surface areas.

Graphitic filaments of carbon and "cauliflower" graphitic structures are formed from essentially the same process, that is, by the decomposition of methane on $\mathrm{Fe}$, Co, or $\mathrm{Ni}$ surfaces. On small crystallites, which are called "growth" crystals, catalytic decomposition of methane to carbon and hydrogen occurs at one of the crystal faces. The carbon so formed then diffuses through the crystallite and re-emerges at the opposite surface to form a hollow graphitic filament with a diameter approximately the size of the metal crystallite. ${ }^{38}$ on larger crystallites "cauliflower-like" eruptions of graphitic carbon occur. ${ }^{39}$ The fibers posses high mechanical strength ${ }^{43}$, which they can impart to the char, and the "cauli- 
flower" structures have fairly high surface areas. In this way methane treatment can upgrade char by desulfurizing it, by producing $\mathrm{Fe}^{\circ}$ "growth" crystallites, and by growing carbon filaments and/or graphitic "cauliflower" structures.

Since the formation of free radicals by the rupture of coal bonds during mild gasification is believed to be an important step in the production of 1 iquids and chars, we have recently attempted to enhance the yields of chars from IBC1.04 coal using free radical promoters. It is well known that pyrite ${ }^{4-46}$ plays a critical role in generating free radicals in coal at about $500^{\circ} \mathrm{C}$. Though pyrite acts as a catalyst in promoting free radicals in coal, and thus may help in better polymerizing the coal, it unfortunately adds sulfur into the char. Also, pyrite does not retard agglomeration of the char during mild gasification. Therefore, any free radical promoter added to the clean coal should not only affect the free radical concentration but should also inhibit the agglomeration of the char.

It is well known that clay minerals display a number of cataIytic activities including polymerization, desulfurization, cracking, and hydrogenation ${ }^{47}$. Yet the role in mild gasification has been ignored. Granted that mineral matter in coal contains a significant amount of kaolinite and illinite clays; however, it is the naturally occurring smectites, which display enhanced catalytic activities due to their very large surface areas and uncompensated edge structures. EPR measurements ${ }^{45}$ performed under vacuum show that montmorillonites are effective promoters of free radicals in coal at about $500^{\circ} \mathrm{C}$. Our recent, preliminary mild gasification experiments on IBC-104 coal with various cation exchange smectites reveal that all smectites, when appropriately dispersed in coal, retard the agglomeration of char at $500^{\circ} \mathrm{C}$ under $\mathrm{CH}_{4} / \mathrm{O}_{2}$ mixture, and, depending upon the exchanged cation of the smectite or type of smectite, the yields of liquids and chars are selectively enhanced.

During the first year of this project it was found that the reactive gases $\left(\mathrm{CH}_{4}, \mathrm{He} / \mathrm{O}_{2}, \mathrm{CH}_{4} / \mathrm{O}_{2}\right.$, and $\left.\mathrm{H}_{2}\right)$ dissolve in softened coal and convert some coal mineral matter into catalysts. Adding clays increases coal reactivity because clays exhibit catalytic properties for methane activation, prevent coal agglomeration, and modify the geometric structure of the coal surfaces. DSC measurements show that clean coal devolatilizes at lower temperatures than as-received coal and that preoxidation lowers devolatilization temperatures. specifically, kaolinite increases char yields from pyrolysis of IBC-102 coal in He. In-situ diffuse reflectance FTIR spectra of thermal decompositions of coal reveal changes in $-\mathrm{CH}_{3}$ spectra which suggest either increased $-\mathrm{CH}_{3}$ content in the char or altered physical structure of $-\mathrm{CH}_{3}$. Also, phenol groups play an important role in cross-linking the coal structure when coal is thermally treated. 
EXPERIMENTAL PROCEDURE

\section{Materials}

Coal samples IBC-101, IBC-102, and IBC-104 were obtained from the Illinois Basin Coal Sample Program. They contain respectively, $40.9 \%, 39.8 \%$ and $30.6 \%$ volatile matter, $10.5 \%, 6.8 \%$ and $38.3 \%$ ash, $14.9 \%, 14.2 \%$ and $10.2 \%$ moisture, and $4.4 \%$, $3.3 \%$ and $3.9 \%$ sulfur. Coal samples were first ground in a planetary ball-mill to reduce particle size to $<75 \mu \mathrm{m}$. Then, further ground under water in a micro-rapid Brinkman mill to reduce the particle size to $<37 \mu \mathrm{m}$. The water-ground coal was dried at $24^{\circ} \mathrm{C}$ under flowing nitrogen and sieved to recover the < $37 \mu \mathrm{m}$ particle-sized coal. Clean IBC-102 coal was prepared as described in the previous quarterly report.

Methane (UHP grade) and helium were obtained from MG Industries, Scientific Gas Division. The gases were dried over activated molecular sieve were further purified by flowing through a $\mathrm{Mn} / \mathrm{SiO}_{2}$ trap to remove oxygen.

\section{BTU Measurements}

BTU measurements were performed in coal testing laboratory of Mechanical Engineering and Energy Processes Department of Southern Illinois University.

\section{High-Temperature in-situ Diffuse Reflectance-Fourier Trans- form Infrared (HT-ISDR-FTIR) Measurements:}

In this quarter, we extended our HT-ISDR-FTIR measurements to IBC-101 coal. The pyrolytic behavior was probed by placing the as-received coal sample in a DRIFT cup mounted in a diffuse reflectance center-focused accessory in the optical compartment of a Nicolet 740 FTIR spectrometer. The spectrometer was linked to a Nicolet 620 computer and was fitted with a fast response, high sensitivity liquid nitrogen cooled MCT detector. The HT-ISDR-FTIR measurements were accomplished with the help of a Spectra-Tech high-temperature high-pressure catalytic chamber. The heating chamber was connected via a flexible, stainless steel tube to a $\mathrm{He}$ gas cylinder. The He gas, which flows through our catalytic chamber, mounted in the optical beam path, was forced into the chamber via a liquid nitrogen trap. A positive pressure of He gas was maintained in the catalytic chamber to ensure that no back-streaming of air would occur at the He gas outlet of the chamber. The znse dome over the catalytic chamber was continuously flushed with cold water to ensure that the Znse crystals would not undergo distortion. Two hundred scans at a resolution of $4 \mathrm{~cm}^{-1}$ were collected at each desired temperature. The heater assembly, mounted underneath the sample cup containing the coal, was used to alter and control the sample temperature to + or $-1{ }^{\circ} \mathrm{C}$. Tap water was circulated through the heating chamber in such 
a way that while the heater and the sample were held at the desired high temperature the rest of the chamber was at the tap water temperature. The overall design of our HT-ISDRFTIR system is shown in Figure 1.

\section{RESULTS AND DISCUSSION}

\section{High Temperature in-situ Diffuse Reflectance-Fourier Trans- form Infrared (HT-ISDR-FTIR) Measurements}

\section{(a) Effects of Drying on IBC-101 Coal Structure}

It is now generally believed that coal's structure is composed of complex macromolecular networks containing many covalent and noncovalent cross-links. Among the noncovalent cross-links, hydrogen bonding is assumed to play a crucial role in sustaining the macromolecular structure of coal. In fact, Larsen et al. ${ }^{48}$ have suggested that for Illinois coals the ratio of the hydrogen-bonded cross-links to covalent cross-links is more than 5. If hydrogen-bonded cross-links are dominant in IBC-101 coal, then a thermal process, such as pyrolysis, will be significantly affected by the behavior of these cross-links. Miura et al. ${ }^{49}$ from their differential scanning calorimetry (DSC) and FTIR measurements on various coals have argued that hydrogen bonds are thermally broken on subjecting the coal to a thermal treatment at 100 - $200^{\circ} \mathrm{C}$. Since the normally accepted drying process of coal requires treatment at about $110^{\circ} \mathrm{C}$, it is important to understand how the drying process affects the structure of coal.

To understand how the drying process affects the structure, if any, of IBC-101 coal, we conducted ISDR-FTIR measurements. This was accomplished by first recording the diffuse reflectance-FTIR spectrum at $25^{\circ} \mathrm{C}$ of as-received IBC-101 coal and then raising the temperature of the sample cell to $100^{\circ} \mathrm{C}$. The sample was held at $100^{\circ} \mathrm{C}$ under He flow for 30 minutes prior to recording its diffuse reflectance-FTIR spectrum. The diffuse reflectance-FTIR spectrum of the dried sample was subtracted from the spectium of the freshly ground coal. The resulting difference spectrum is depicted in Figure 2 .

As can be seen from the difference spectrum (see Figure 2), the drying process affects the IBC-101 coal's diffuse reflectance-FTIR spectrum in two distinct frequency ranges, i.e., $3700-3000 \mathrm{~cm}^{-1}$ and $1800-1600 \mathrm{~cm}^{-1}$. In the 3700 $3000^{\prime} \mathrm{cm}^{-1}$ frequency range, a sharp, positive band appears at $3652 \mathrm{~cm}^{-1}$. This sharp band is accompanied by a very broad positive band at $3217 \mathrm{~cm}^{-1}$. In the $1800-1600 \mathrm{~cm}^{-1}$ range a negative band appears at $1753 \mathrm{~cm}^{-1}$, while a positive band is observed at $1645 \mathrm{~cm}^{-1}$. These observations imply drying the IBC-101 coal causes intensity losses at 3656,3217 , and 1645 
$\mathrm{cm}^{-1}$ and intensity gaines at $1753 \mathrm{~cm}^{-1}$.

From their FTIR measurements on heating Taiheiyo coal at $170^{\circ} \mathrm{C}$ Miura et al. ${ }^{9}$ report spectrum intensity increases above $3400 \mathrm{~cm}^{-1}$ and decreases between 3400 and $3000 \mathrm{~cm}^{-1}$. They attribute these changes to weakening of self-associated $\mathrm{OH}$ groups and $\mathrm{OH}$-ether hydrogen bonded groups in coal when coal is pyrolyzed at $170^{\circ} \mathrm{C}$. However, on drying our IBC-101 coal, we observe no intensity decrease at either $3400 \mathrm{~cm}^{-1}$ (self-associated OH groups) or $3300 \mathrm{~cm}^{-1}$ (OH-ether hydrogen bonds). Therefore, we discount the theory that hydrogen bonds in this coal are either broken or weakened on drying. It is more reasonable to believe that water is lost from coal on heating at $100^{\circ} \mathrm{C}$.

Liquid water produces strong, broad vibrations around 3400 $\mathrm{cm}^{-1}$ in water's stretching region while a medium intensity band at $1620 \mathrm{~cm}^{-1}$ is observed in water's bending region. As can be seen from Figure 2, no broad, negative bands are observed in the difference spectrum at $3400 \mathrm{~cm}^{-1}$. Therefore, we rule out the presence of physically trapped, but unbonded, water in our coal sample. The fact that a sharp, negative band at $3652 \mathrm{~cm}^{-1}$ is observed in the difference spectrum (Figure 2) raises the possible existence of virtually free $\mathrm{O}-\mathrm{H}$ groups in coal. Our previous studies 50 on water's structure in Illinois coal have suggested that some water is hydrogen bonded to oxygen functional groups in coal, e.g.,<smiles>O=C(O)COCCO</smiles>

and

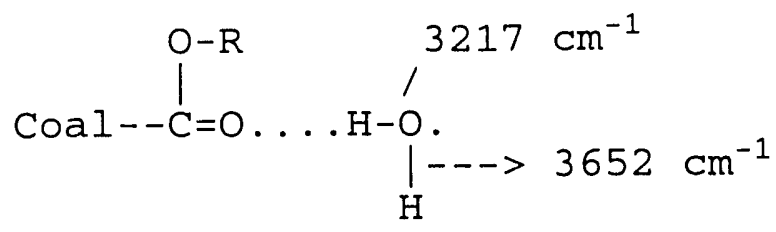

If water is hydrogen bonded to coal though one of its hydrogens, as indicated above, then its other hydrogen will produce almost a free $\mathrm{O}-\mathrm{H}$ oscillator. On drying the coal at $100^{\circ} \mathrm{C}$, the hydrogen bonded water is expected to evaporate from coal. Thus, removal of the hydrogen bond perturbations of the Coal-COOH and Coal-COOR groups will change their dipole moments. If such is the case, our difference spectrum will lose intensity loss at about $3652 \mathrm{~cm}^{-1}$ (free $\mathrm{O}-\mathrm{H}$ groups), $3217 \mathrm{~cm}^{-1}$ (hydrogen bonded O-H oscillator), and 1645 (H-O-H bending oscillator) and will gain intensity at about $1730-1700 \mathrm{~cm}^{-1}$ (for $-\mathrm{COOH}$ groups) and $1750-1735$ $\mathrm{cm}^{-1}$ (-COOR groups). This is precisely what we observe. since the dipole moment associated with $-\mathrm{COOH}$ and $-\mathrm{COOR}$ 
groups changes on drying coal, it appears that coal rearranges its structure. The graph presented in Figure 3 further supports our argument that the changes observed in intensities at $3652,3217,1765$, and $1645 \mathrm{~cm}^{-1}$ are associated with hydrogen bonded water in coal. As can be seen from this figure, no further change in intensities of the 3653 and $1765 \mathrm{~cm}^{-1}$ bands occurs beyond $200^{\circ} \mathrm{C}$. This is to be expected as most of water is lost from coal by $200^{\circ} \mathrm{C}$.

\section{(b) in-situ Diffuse Reflectance-FTIR Probe of Coal Pyrolysis at $17^{\circ} \mathrm{C}<\mathrm{T}<627^{\circ} \mathrm{C}$}

It has been argued that thermally induced cross-linking in coal retards liquid yields under mild-gasification conditions ${ }^{51}$. However, the mechanism(s) of cross-linking and the condition under which extensive cross-linking in coal occurs are not well established. As an initial strategy to optimize yields of chars and liquids from Illinois coals, we undertook HT-ISDR-FTIR measurements on IBC-101 coal at $17^{\circ} \mathrm{C}$ $<\mathrm{T}<627^{\circ} \mathrm{C}$ in a spectra-Tech high-temperature highpressure catalytic chamber. We conducted such measurements to provide enough information not only to understand the mechanisms of cross-linking in coal but also to provide information to enhance yields of chars or liquids.

On subjecting IBC-101 coal to pyrolysis at $27^{\circ} \mathrm{C}-627^{\circ} \mathrm{C}$ under He gas, a highly complex set of ISDR-FTIR spectra result (Figure 4). The spectra reproduced in Figure 4 clearly show a dramatic change around $400^{\circ} \mathrm{C}$. At $400^{\circ} \mathrm{C}$ the FTIR spectrum changes from a coal-like spectrum to a tarlike spectrum. The reason for this change is readily explained.

Since znse dome over the reactor chamber is kept at tap water temperature, the expelled liquids condense on the cold dome. Thus, we have a unique opportunity to monitor the yields and structures of the liquids under in-situ pyrolytic conditions. To facilitate mechanistic understanding of pyrolysis, we generated a set of difference ISDR-FTIR spectra, i.e.,

Difference Spectrum (at $\mathrm{T}\left({ }^{\circ} \mathrm{C}\right)=$ ISDR-FTIR Spectrum (at $\left.\mathrm{T}\left({ }^{\circ} \mathrm{C}\right)\right)$ - ISDR-FTIR Spectrum (at $27^{\circ}$ ).

The difference spectra at $100^{\circ} \mathrm{C}, 200^{\circ} \mathrm{C}, 300^{\circ} \mathrm{C}$, and $273^{\circ} \mathrm{C}$ are shown in Figure 5, while the difference spectra at $400^{\circ} \mathrm{C}$, $500^{\circ} \mathrm{C}$, and $600^{\circ} \mathrm{C}$ are shown in Figure 6 . Changes occur throughout the $3700-600 \mathrm{~cm}^{-1}$ range; however, the major changes in the spectra are in five distinct frequency ranges, i.e., $3700-3300 \mathrm{~cm}^{-1}$ range, $3050-2800 \mathrm{~cm}^{-1}$ range, $1800-1400 \mathrm{~cm}^{-1}$ range, $1300-1100 \mathrm{~cm}^{-1}$ range, and $900-700$ $\mathrm{cm}^{-1}$ range.

The $\mathrm{C}-\mathrm{H}$ stretching modes, due to the presence of aromatic 
(3045 $\left.\mathrm{cm}^{-1}\right)$, methyl (2954 and $2885 \mathrm{~cm}^{-1}$ ), and methylene (2926 and $2854 \mathrm{~cm}^{-1}$ ) groups in coal, dominate the frequency range $3050-2800 \mathrm{~cm}^{-1}$. Changes in intensity, relative to the spectrum at $27^{\circ} \mathrm{C}$ of antisymmetric $\mathrm{C}-\mathrm{H}$ stretch of methyl $\left(2956 \mathrm{~cm}^{-1}\right)$, antisymmetric $\mathrm{C}-\mathrm{H}$ stretch of methylene (2926 $\mathrm{cm}^{-1}$, and symmetric stretch of methylene $\left(2854 \mathrm{~cm}^{-1}\right)$, were calculated from the difference spectra of Figures 5 and 6 . These changes are graphed in Figure 7 for the methyl and methylene groups.

Aromatic vibrations are the major oscillators at $3037 \mathrm{~cm}^{-1}$ and $900-700 \mathrm{~cm}^{-1}$. The $3037 \mathrm{~cm}^{-1}$ band can be assigned to C$\mathrm{H}$ stretch of aromatic groups, while the bands in the 900 $700 \mathrm{~cm}^{-1}$ range can be assigned to the aromatic $\mathrm{C}-\mathrm{H}$ out-ofplane bending modes of aromatic rings with various substitution patterns. Three distinct bands at $862,816 \mathrm{~cm}^{-1}$ and $752 \mathrm{~cm}^{-1}$ are observed in the difference spectrum at 327 $273^{\circ} \mathrm{C}$. Based on the published literature 52,53 , the $862 \mathrm{~cm}^{-1}$ band is assigned to rings with an isolated $\mathrm{C}-\mathrm{H}$ group surrounded by substituted carbons and the $816 \mathrm{~cm}^{-1}$ band is assigned to a substituted benzene ring with two neighboring $\mathrm{H}$ and/or angular condensed ring system. The band at $752 \mathrm{~cm}^{-}$ 1 is attributed to O-substituted benzene rings and/or condensed ring system. The changes in intensities of aromatic bands at $3037,862,816$, and $752 \mathrm{~cm}^{-1}$ are graphed in Figure 8 .

Results presented in Figures $4,5,6,7$, and 8 can be interpreted as follows:

(a) As the pyrolysis temperature of the IBC-101 coal is raised to $300^{\circ} \mathrm{C}$, the vibrational bands of the condensed liquids (on the inner surface of the dome) begin to appear in the difference spectrum. Therefore, we conclude that the thermal decomposition of IBC-101 coal initiates at a much lower temperature than has been so far believed. It should also be noted that for IBC-102 coal, liquids first appear at $350^{\circ} \mathrm{C}, 50^{\circ} \mathrm{C}$ higher than for IBC-101 coal. Though liquid yields are lower at $300^{\circ} \mathrm{C}$ for IBC-101 coal, the reason for the lower thermal decomposition temperature is not clear at present.

(b) On further increasing pyrolysis temperature, more and more liquids are produced. The maximum yield of liquids occurs at $500^{\circ} \mathrm{C}$ for IBC-101 coal, while similar data for IBC-102 coal indicate that maximum liquids are produced at $550^{\circ} \mathrm{C}$.

(c) As can be seen from Figure 7, the 2954, 2926 and 2854 $\mathrm{cm}^{-1}$ oscillators reach their maximum intensity at $500^{\circ} \mathrm{C}$. Above $500^{\circ} \mathrm{C}$ the intensity of $-\mathrm{CH}_{3}$ and $-\mathrm{CH}_{2}$ groups decreases. There could be two possible explanations for the decrease in intensity of methyl and methylene bands. One logical explanation could be that the liquids produced above $500^{\circ}$ are much higher in aromatic content, thus, effectively reducing 
the concentration of aliphatic groups in the overall liquid yield. The second possible explanation could be that aliphatic groups produced in the temperature range $250^{\circ} \mathrm{C}-$ $500^{\circ} \mathrm{C}$ belong to liquids which have low boiling points. A careful examination of the difference spectra in Figures 5 and 6 suggests that while the intensities of methyl and methylene vibrations decrease above $500^{\circ} \mathrm{C}$, the decrease in other functional groups' intensities is only marginal.

(d) To probe how the pyrolysis temperature affects the aromatic content of liquids produced, we generated the intensity ratio of aliphatic $\mathrm{C}-\mathrm{H}$ stretch $\left(3000-2760 \mathrm{~cm}^{-1}\right)$ modes to aromatic $\mathrm{C}-\mathrm{H}$ out-of-plane bending $\left(920-670 \mathrm{~cm}^{-1}\right)$ modes. The intensity ratio as a function of pyrolysis temperature is graphed in Figure 9. It can be clearly seen that as the pyrolysis temperature is increased, the aliphatic-to-aromatic ratio's value first increases reaching a maximum at $300^{\circ} \mathrm{C}$ and then progresively decreases. It appears from this result that the long-chain aliphatic hydrocarbons, under He gas environment, crack into small fragments at $200^{\circ} \mathrm{C}<\mathrm{T}<350^{\circ} \mathrm{C}$ and devolatilize. BraekmanDanheux et al. 54 from their pyrolysis of exinite-rich coals have reported similar behavior.

\section{(c) ISDR-FTIR Spectra of Liquids Produced under Pyrolysis}

Figure 10 reproduces the FTIR spectrum of the liquids produced at $600^{\circ} \mathrm{C}$. The observed bands along with their assignments are listed in Table 1. 
Table 1

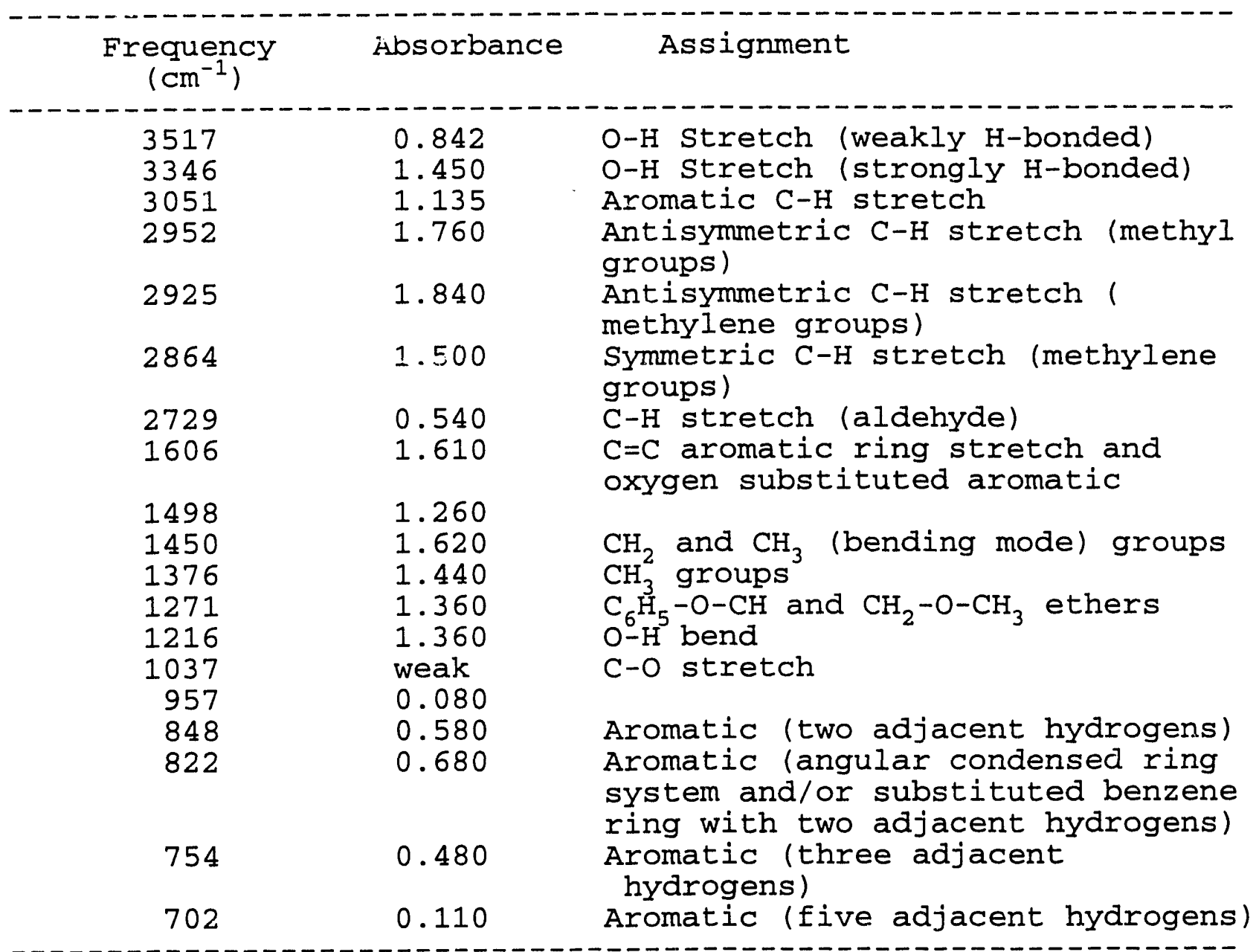

It has been argued ${ }^{54}$ that under mild-gasification conditions coal undergoes fragmentation to produce a complex mixture of liquids. These include alkanes and alkenes from $\mathrm{C}_{6}$ to $\mathrm{C}_{16}$, benzene, toluene, xylenes, ethylbenzene, phenol, cresols, xylenols, naphthalene, methylnaphthalenes, indane, indene, fluorene, chrysene, phenanthrene, and pyrene. If such is the case then the observed spectrum, reproduced in Figure 10, is a complex spectrum which reflectsing various liqiuids in different concentrations. Obviously the analysis is not straightforward. To analysis the liquids produced under mild-gasification conditions, we are in the process of generating an extensive FTIR library of those chemicals suggested present in the tar liquids.

\section{Chars preparation in different atmospheres.}

We prepared different chars by treating coals with $\mathrm{CH}_{4}$ or helium at $700^{\circ} \mathrm{C}$ for $24 \mathrm{hrs}$. The effect of this treatment on the BTU values and sulfur contents was examined. 
Table 2. ETU values of coals and chars.

\begin{tabular}{|c|c|}
\hline Sample description & $\mathrm{BTU} / \mathrm{Ib}$ \\
\hline IBC 101 as received & 12137 \\
\hline IBC 101 in $\mathrm{CH}_{4}$ & 11276 \\
\hline IBC 101 in $\mathrm{He}$ & 10989 \\
\hline IBC 102 as received & 12848 \\
\hline IBC 102 in $\mathrm{CH}_{4}$ & 12233 \\
\hline IBC 102 in $\mathrm{He}$ & 11734 \\
\hline Clean 102 & 13677 \\
\hline Clean 102 in $\mathrm{CH}_{4}$ & 12660 \\
\hline Clean 102 in $\mathrm{He}$ & 12023 \\
\hline IBC 104 as received & 6916 \\
\hline IBC 104 in $\mathrm{CH}_{4}$ & 6554 \\
\hline IBC 104 in $\mathrm{He}$ & 6417 \\
\hline Clean 104 & 8575 \\
\hline
\end{tabular}

As may be seen in Table 2, clean coals have larger BTU values than "as received" coals. This may be explained in the following way: removing the mineral matter, which has zero BTU value, increases values of remaing carbonaceous material (per weight unit).

Generally, pyrolysis of coals at $700^{\circ} \mathrm{C}$ decreases their BTU value. It is due to removal of volatile material from the coal matrix. However, the BTU value of coals after $\mathrm{CH}_{4}$ treatment is higher than after He treatment, which suppports the view that methane decomposes and deposits carbon at the char surface. 
CONCLUSIONS AND RECOMMENDATIONS

1. It was confirmed that water is hydrogen bonded to oxygen functional groups in coal.

2. Thermal decomposition of IBC-101 coal starts at $300^{\circ} \mathrm{C}$, which is much lower than has been so far believed.

3. Maximum yield of liquids occurs at $500^{\circ} \mathrm{C}$ for IBC 101 coal and at $550^{\circ} \mathrm{C}$ for IBC $102 \mathrm{coal}$.

4. As pyrolysis temperature is increases, aliphaticto-aromatic ratio first increases reaching a maximum at $300^{\circ} \mathrm{C}$ and than progressively decreases.

5. Liquids produced above $500^{\circ} \mathrm{C}$ are much higher in aromatic content, thus, effectively reducing the concentration of aliphatic groups in the overall liquid yield.

6. BTU values of coals after methane treatment is higher than after helium treatment.

\section{REFERENCES}

1. Speight, J.G., 1983, The Chemistry and Technology of Coal, Marcell Dekker, Inc., New York.

2. Berkowitz, N., 1985, The Chemistry of Coal, Elsevier, New York

3. Cypres R., S. Furfari, 1982, Fuel, 61, 721

4. Steiberg, M.M., M.S. Sundaram, 1986, Energy Res. Abstr., Abstr. \# 15465

5. Steinberg, M., 1986, Int. J. Hydrogen Energy, 11, 715

6. Hefta, R.S., H.H. Schobert, W.R. Kube, 1986, Fuel, 65, 1196

7. Khan, M.H., F.Y. Hshieh, L. Headley, 1989, ACS Preprint Fuel Div, $34(4), 1167$

8. Khan M.R., 1989, Fuel, 68, 1522

9. Smith, G.V., T. Wiltowski, 1990, "Chemicals from Coal and Methane", CRSC Final Report.

10. Snape, C.E., 1991, Fuel, 70, 285

11. Pugmire, R.J., M.S. Solum, D.M. Grant, S. Critchfield, 1991, Fuel, 70, 414 
12. Ibarra, J.V., R. Moliner, M.P. Gavilan, 1991, Euel, 70, 408

13. Hodek W., J. Kirschstein, K.H. Van Heek, 1991, Fuel, 70, 424

14. Khan, M.R., 1987, Fuel Science and Technology Internation al, 5, 185

15. Chu, C.I., C.J. Im, B.L. Gillespie, 1989, DOE Report, DE-AC-218MC23289

16. Smith, G.V., T. Wiltowski, J.B. Phillips, 1989, Energy \& Fuels, 3, 541

17. Khan, M.R., F.Y. Hshiech, 1989, ACS Preprints Fuel Div., $34(4), 1245$

18. Daw, C.S., 1989, ACS Preprints Fuel Div,, 34(4), 1256

19. Rostam-Abadi, M., J.A. DeBarr, W.T. Chen, D.P. McCollor, S.A. Benson, 1989, ACS Preprints Fuel Div, 34(4), 1264

20. Wells, W.F., L.D. Smoot, 1991, Fuel, 70, 454

21. Derbyshire, F., 1991, Fuel, 70, 276

22. Kuhn, L., H. Plogmann, 1990, Fuel, 62, 205

23. "Research Program for Illinois Basin Coals", CRSC, Cham paign, Illinois (1984)

24. Gala, H., 1987, "Surface Science of Coal Preparation", DOE Report\#DE-AC22-84PC72571, and references citied therein

25. Malhotra, V.M., M. Saporoshenko, A.C. Kent, 1990, "Modifi cation of Pyrite Surfaces and Preparation of Cleaned Ultra fine Coal", CRSC Final Report

26. Malhotra, V.M., W.R.M. Graham, 1983, Bull. Amer. Phys. Soc., 28, 202

27. Malhotra, V.M., W.R.M. Graham, 1983, Euel, 62, 1255

28. Malhotra, V.M., W.R.M. Graham, 1984, ACS Preprint Div. Petroleum Chem., 29(1), 261

29. Malhotra, V.M., H.A. Buckmaster, 1984, ACS Preprint Div. Petroleum Chem., 29(4), 1232

30. Malhotra, V.M., H.A. Buckmaster, 1985, Fuel, 64, 335

31. Malhotra, V.M., H.A. Buckmaster, 1985, Applied Clay Sci ence, 1，225 
32. Mu, R., V.M. Malhotra, Y.P. Chugh, 1987, "Effects of Heavy Crude Oil Treatment on the Surface Wetting Properties of Coal", in Processing and Utilization of High sulfur coal, Elsevier, New York, pp 94-106

33. Malhotra, V.M., R.D. Moore, 1985, "Thermal Shock of Heavy Oil Formations:FTIR Study", 27th Rocky Mountain Conference for Applied Spectroscopy, Denver, Colorado

34. Malhotra, V.M., Y. Dang, R.Mu, W.A. Helmer, A. Kent, F. Oksus, 1989, "Heavy Oil Fractions Assisted Deewatering and Agglomeration of Ultrafine Bituminous Coal: FTIR, DRIFT, and Photoacoustic-FTIR Measurements", 31st Rocky Mountain Conference for Applied Spectroscopy, Denver, Colorado, \#245

35. Malhotra, V.M., R.N. Zitter, 1989, "Coal-Water Interactions and Preparations of Dewatered Ultrafine Clean Coal", DOE Report \#DE-FC22-88PC88861

36. Wiltowski, T., R. Walker, D. Ellison, G.V. Smith, (in preparation)

37. Dunkerton, L.V., S. Mitra, J.B. Phillips, G.V. Smith, C.C. Hinckley, and Teresa Wiltowska, 1988, FUEL, 67, 967-972

38. Yang, R.T. and F.P. Chen, 1989, J. Catal. 115, 52-64

39. Sacco, A. Jr., F.W.A.H.Geurts, G.A. Jablonski, S. Lee, and R.A. Gately, 1989, J.Catal. 119, 322-341

40. Baird, T., J.R. Fryer, B. Grant, 1974, Carbon, 12, 591-602

41. Lieberman, M.L. and Noles, G.T., 1974, Carbon, 12, 689-693

42. Palmer, H.B., J. Lahaye, and K.C. Hou, 1968, J. Phys. Chem., 72, 348-353

43. Rostrup-Nielsen, J.R., 1984, Catalysis, Science and Tech nology, 5, 1-117

44. Seehra, M.S., G. Ghosz, S.E. Mullins, 1986, Fuel, 65, 1315

45. Ali, M.S., W.R.M. Graham, 1987, ACS Preprints Fuel Div., $32(3), 217$

46. Montano, P.A., G. Granoff, 1980, Euel, 59, 214

47. Ruppert, J.P., W.T. Granquist, T.J. Pinnavalia, 1987, "Catalytic Properties of Clay Minerals" in Chemistry of Clays and Clay Minerals, ed.: A.C.D. Newman, Longman Scien tific \& Technical, Essex, England

48. Larsen, J.W., T. K. Green, and J. Kovac, J. Org. Chem. 50, 
$4729(1985)$.

49. Miura, K., K. Mae, K. Sakurada, and K. Hashimoto, Energy \& Fuels 6, 16 (1992).

50. Mu, R., and V. M. Maihotra, Fuel 70, (1991).

51. Mapstone, J.O., Energy \& Fuels 5, 695 (1991).

52. Painter, P.C., R. W. Snyder, M. Starsinic, M. C. Coleman, D.W. Kuehn, and A. Davis, Appl. Spectroscopy 35, 475 (1981).

53. Chen, P., P. W. -J Yang, and P. R. Griffiths, Euel, 64, 307, (1984).

54. Braekman-Danheux, C., P. Laurent, and K. Pisaneschi, Fuel, 72, $576(1993)$. 


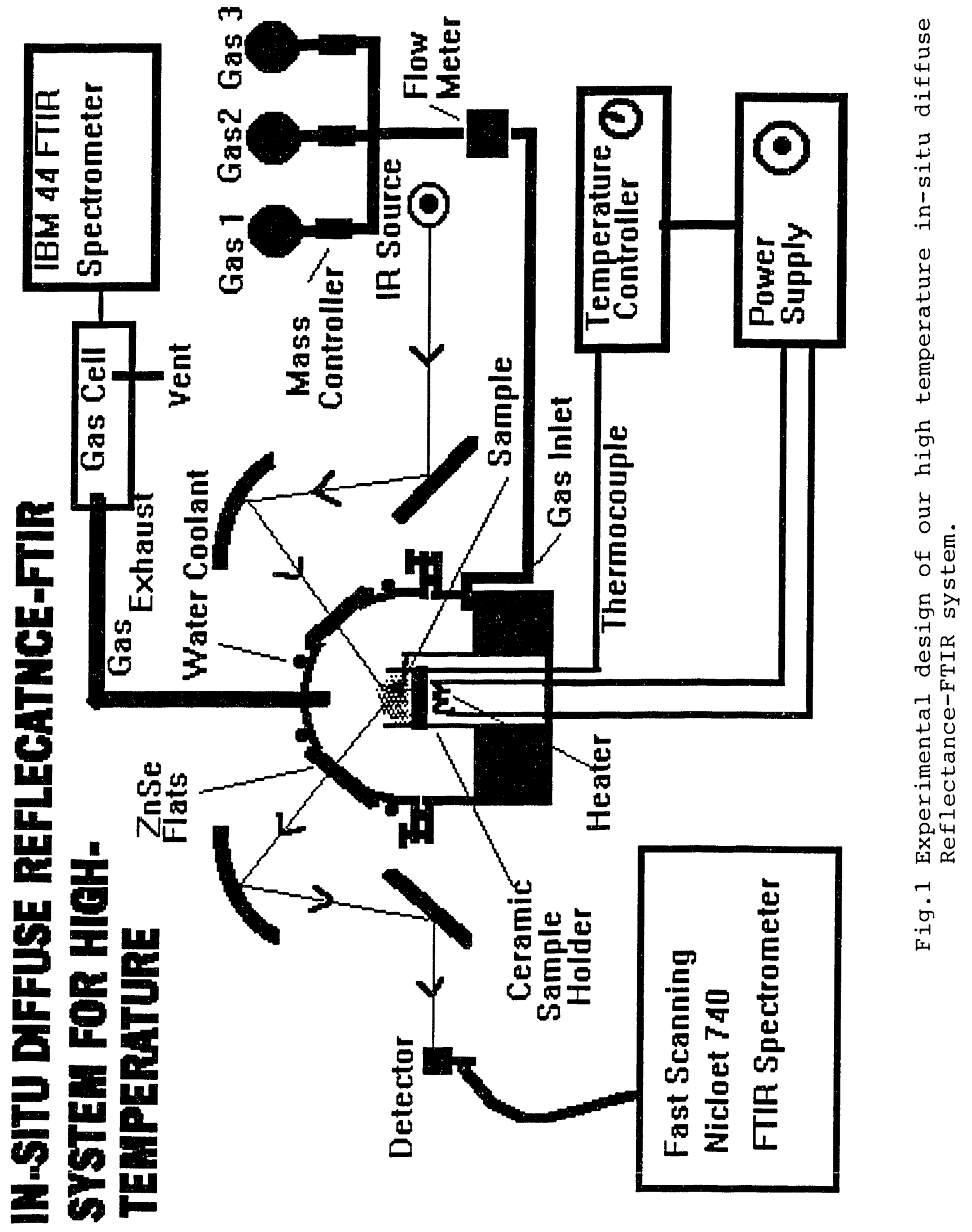


$\therefore \quad \because$

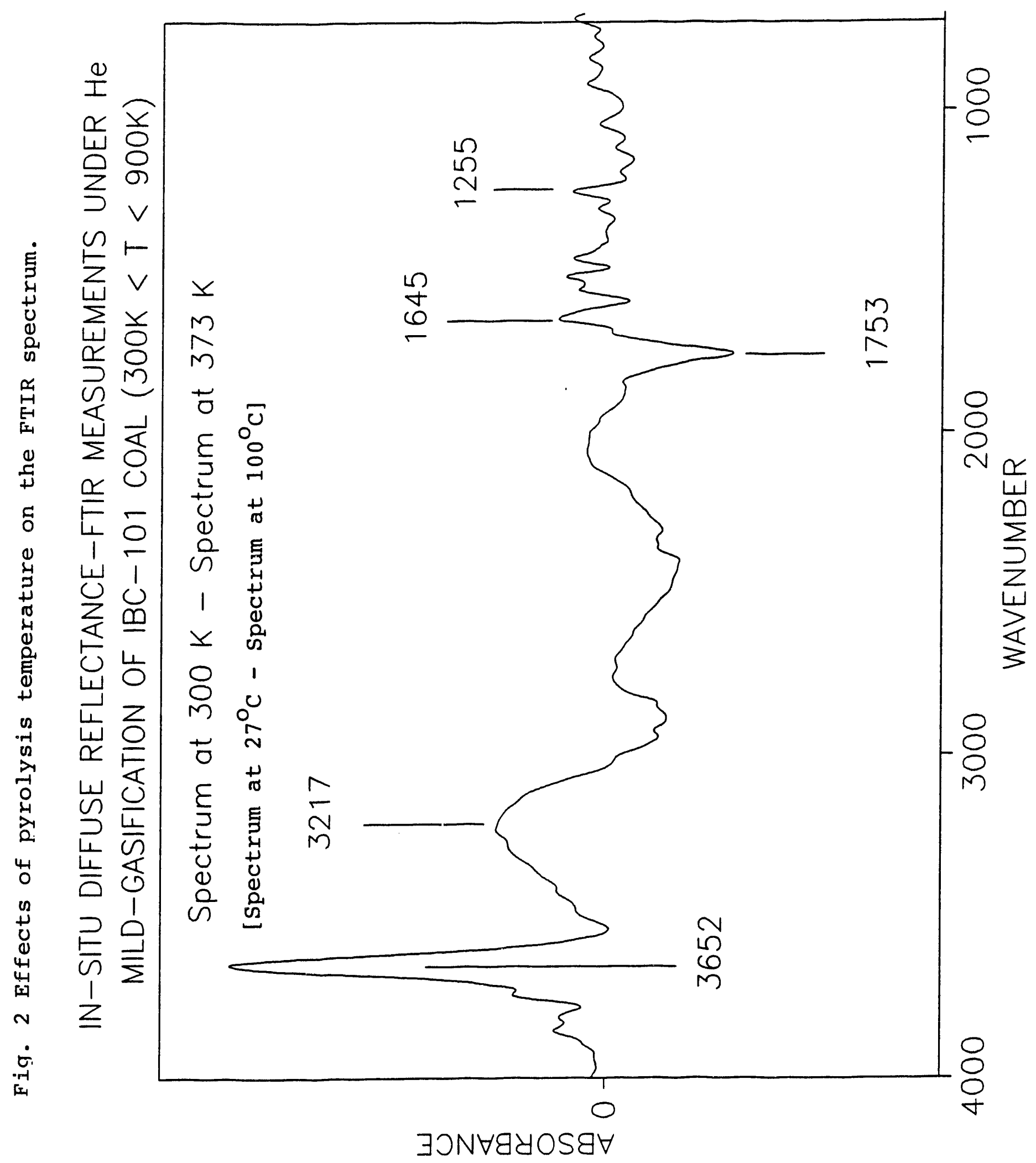


$\therefore \quad \therefore$

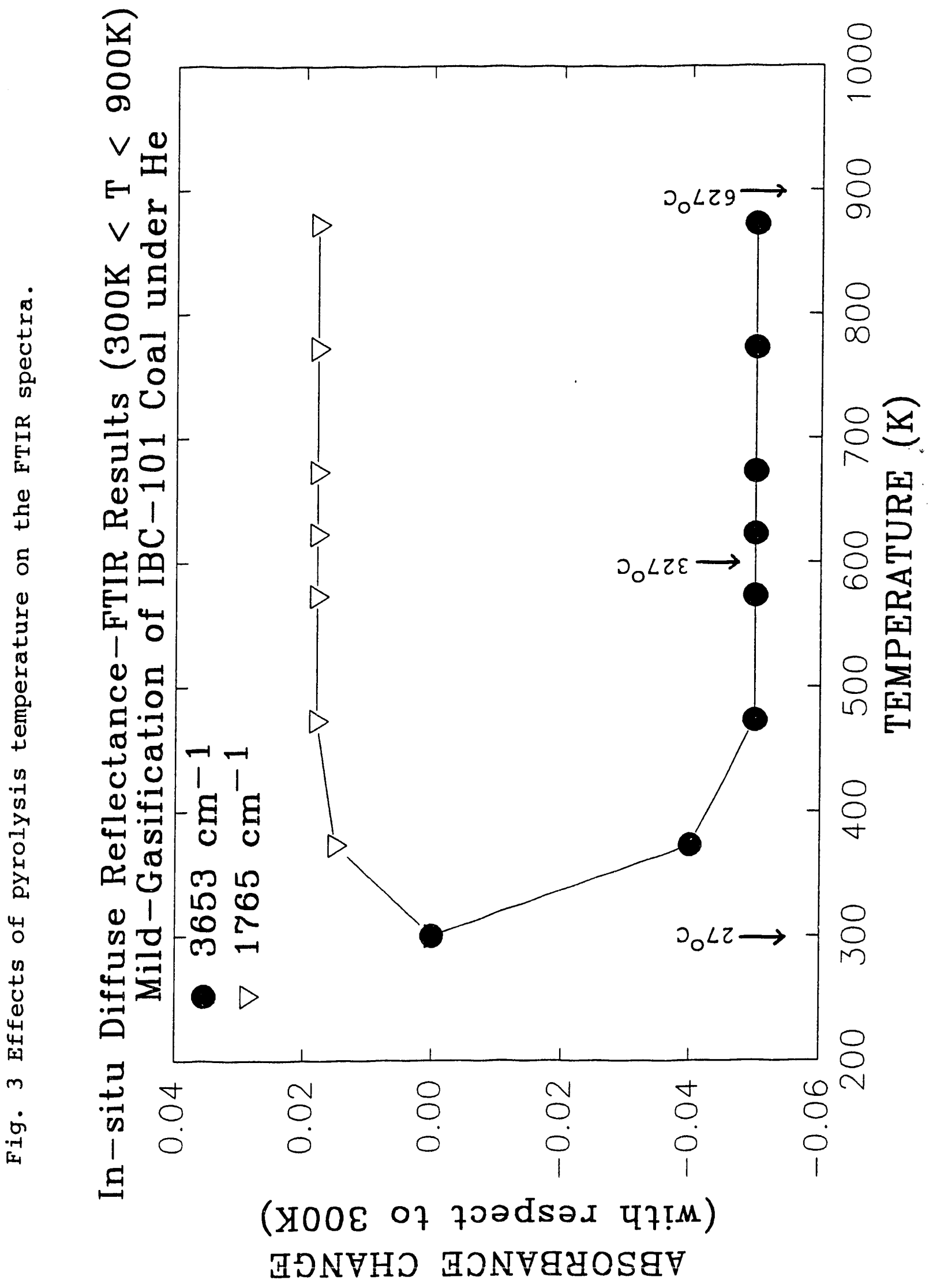


$\therefore \quad \therefore$

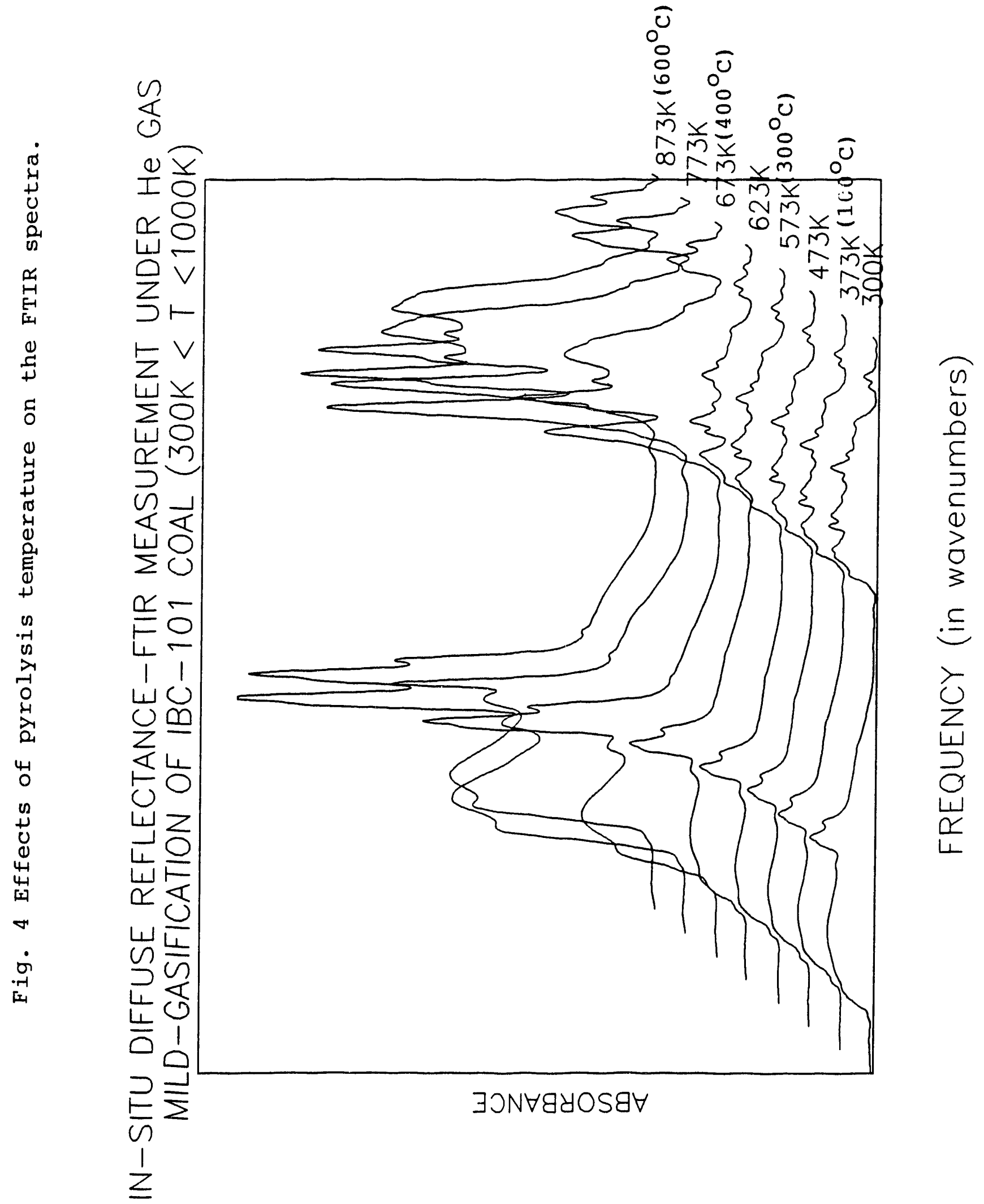


$\therefore \quad \therefore$

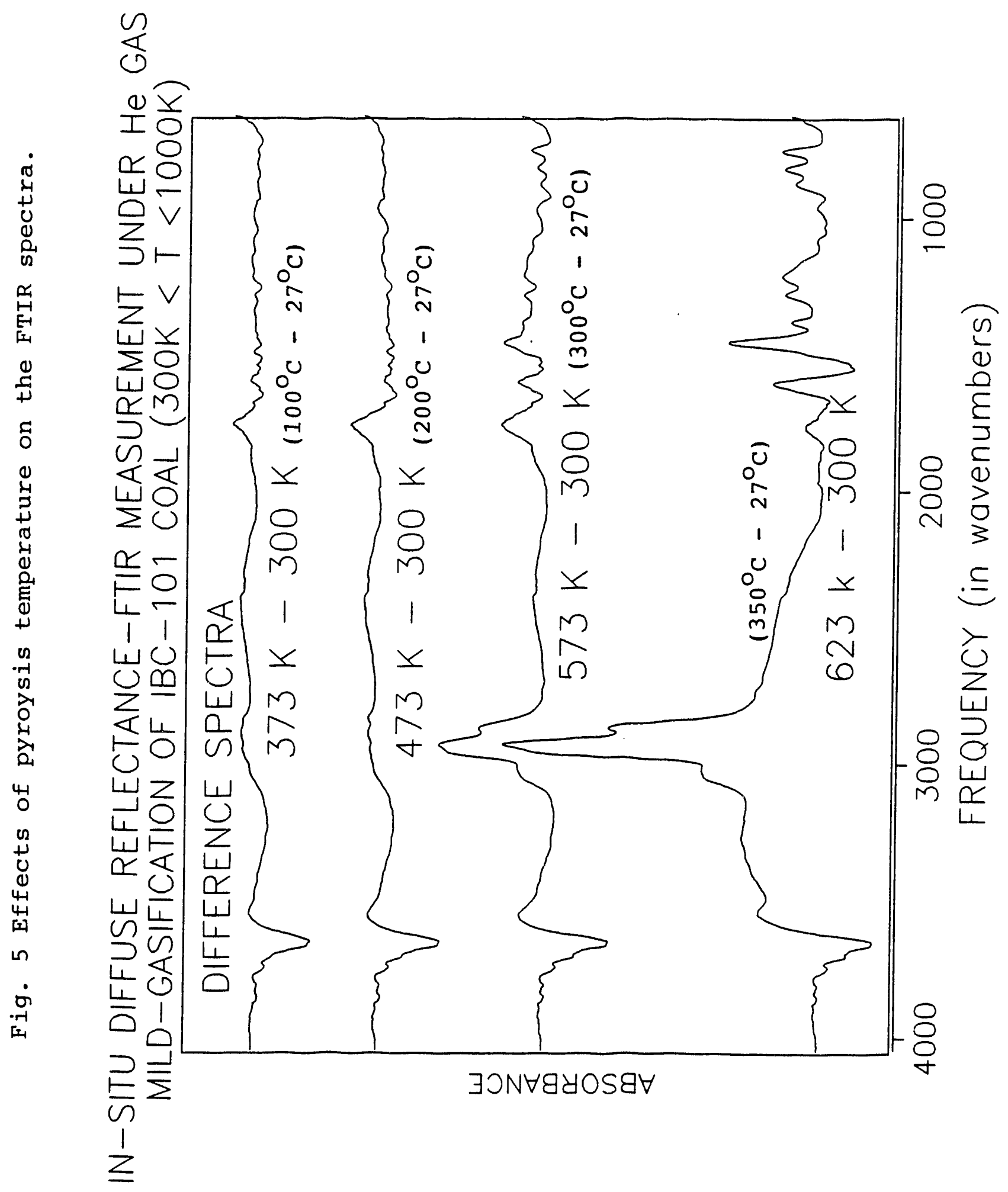




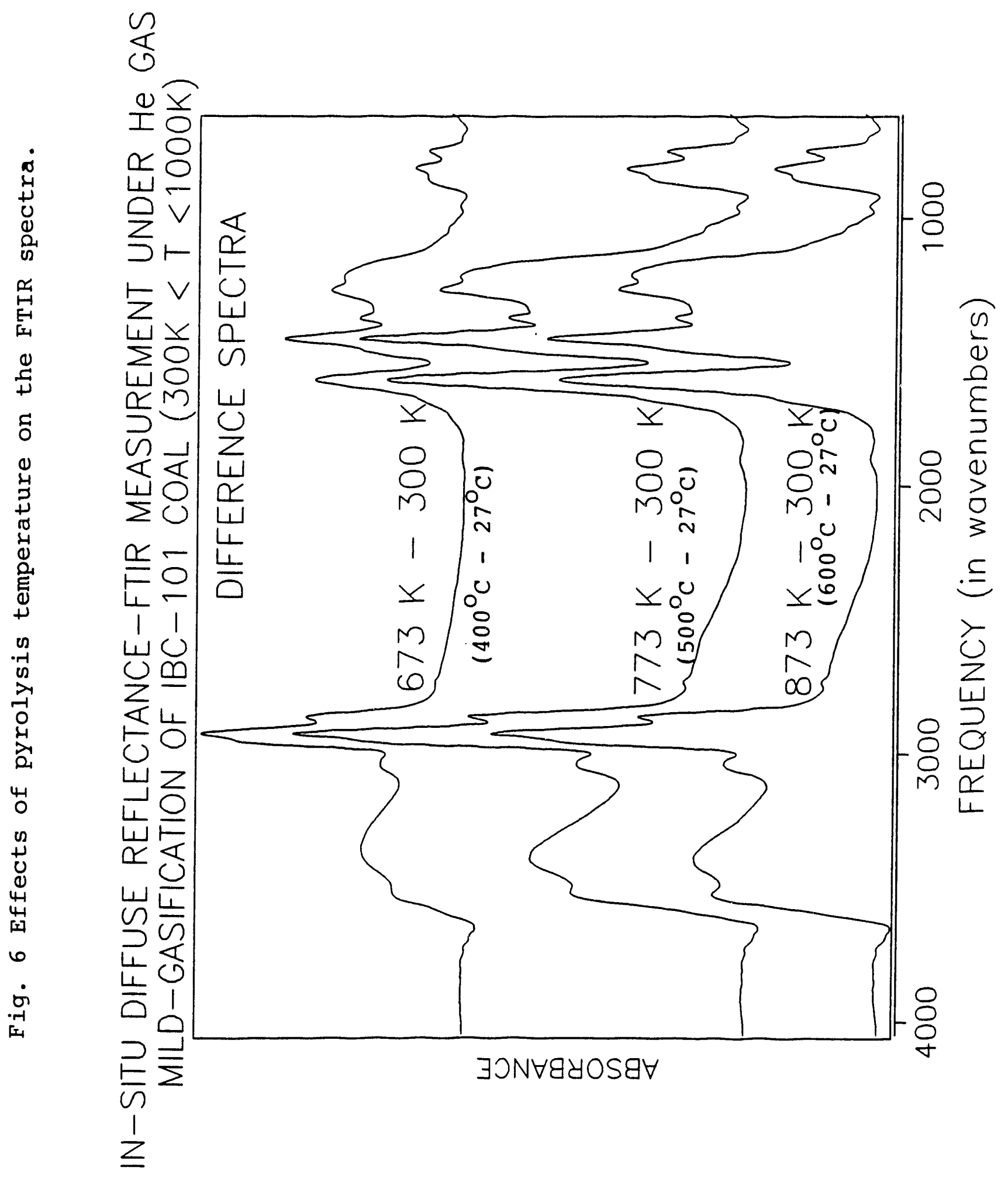




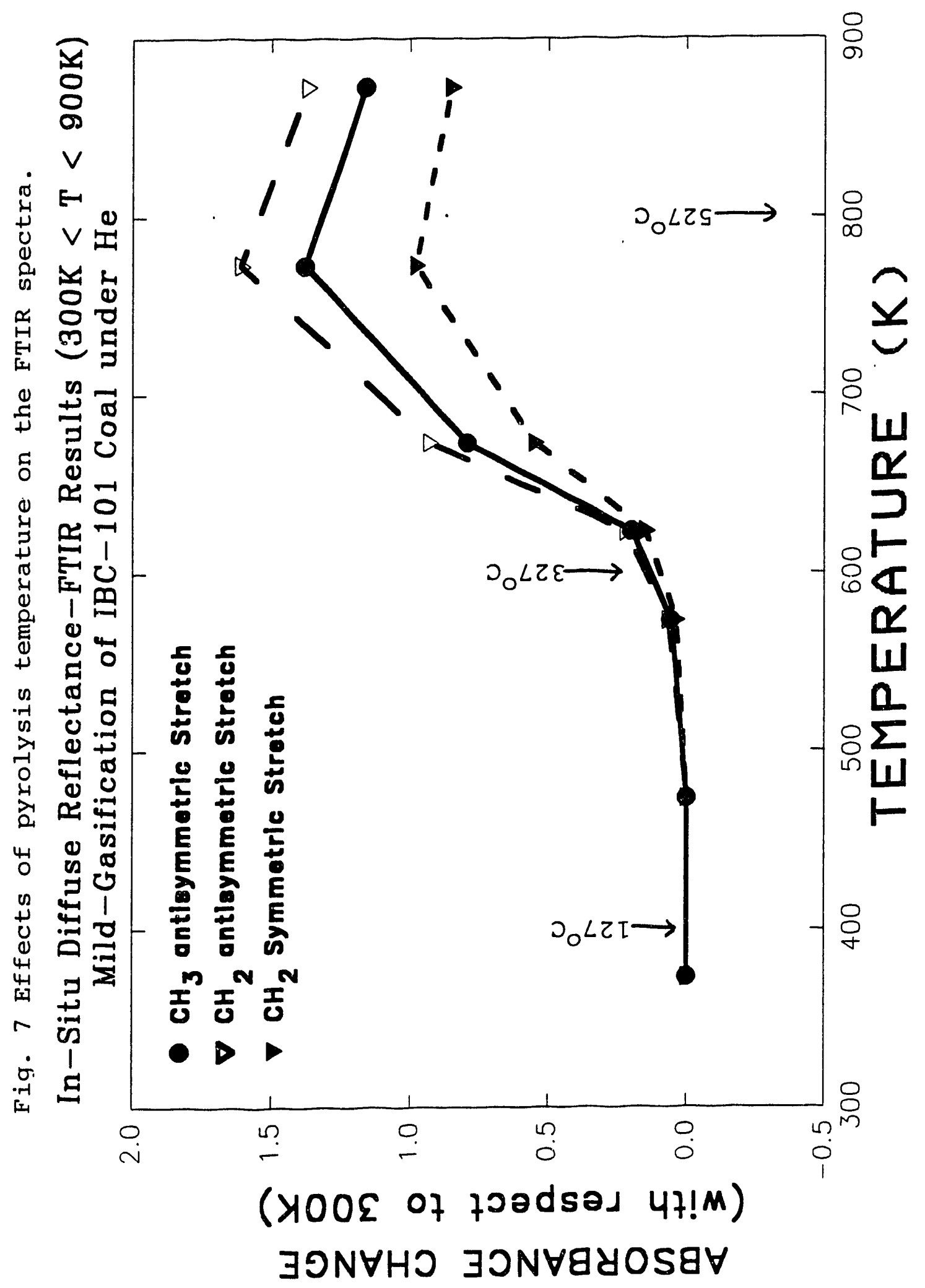




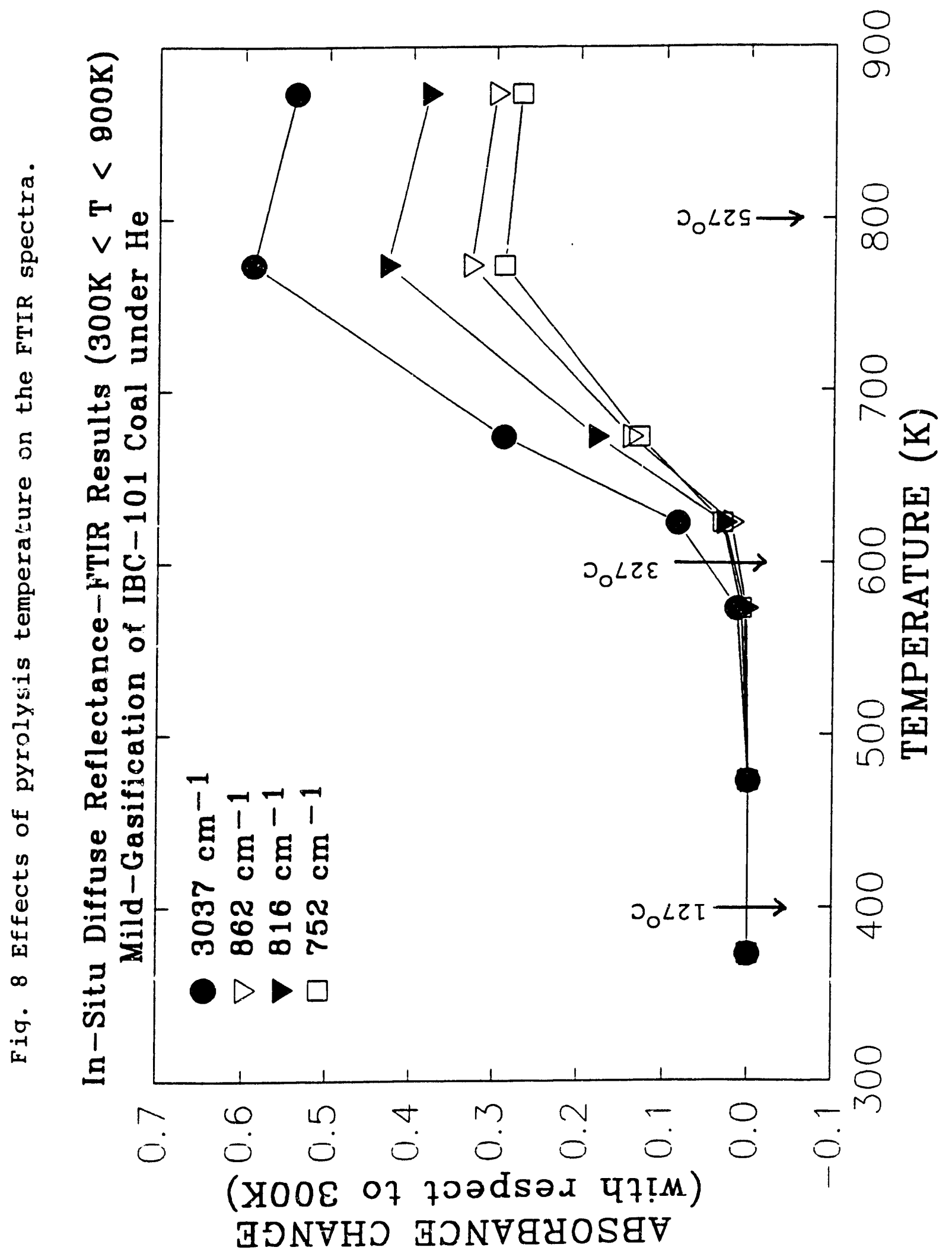




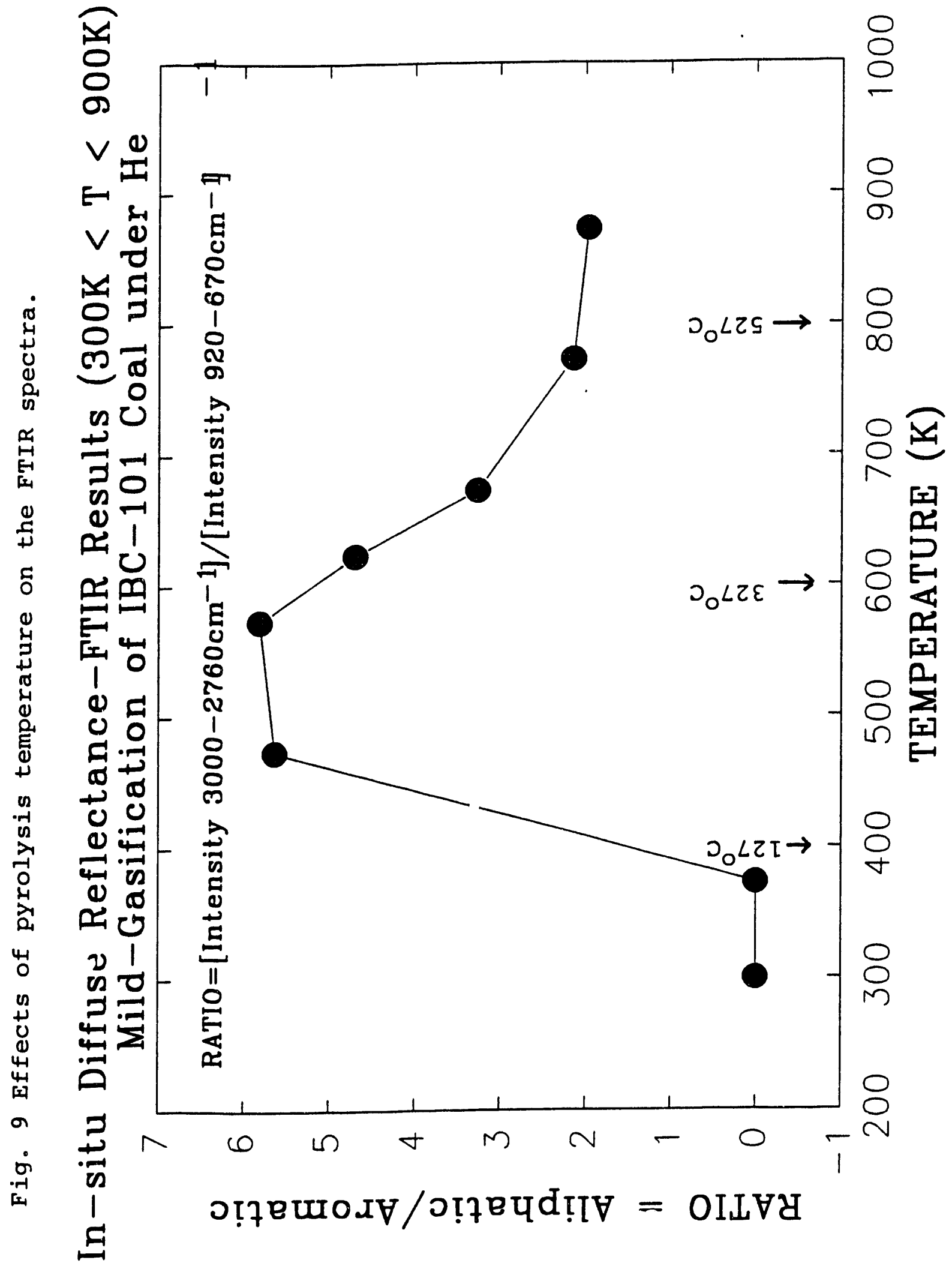



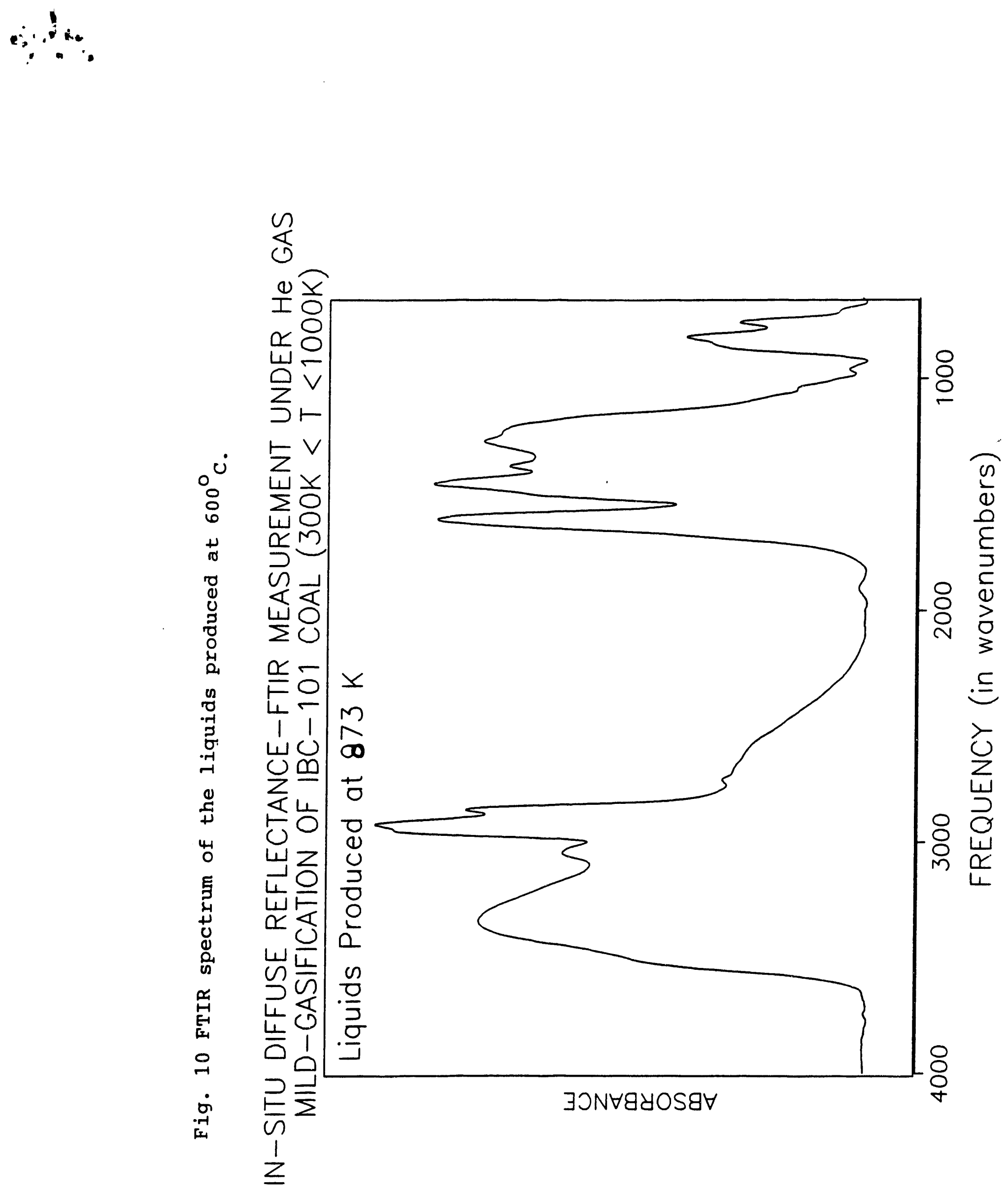
Project Title: CLEAN, PREMIUM-QUALITY CHARS: DEMINERALIZED AND CARBON ENRICHED

Principal Investigator: Gerard V. Smith

Molecular Science Program

Southern Illinois University

Carbondale, IL 62901

(618) 453-7319

Other Investigators:

Vivak M. Malhotra

Department of Physics

Southern Illinois University

Carbondale, IL 62901

Tomasz Wiltowski

Molecular Science Program

Southern Illinois University

Carbondale, IL 62901

Eugeniusz Myszka

Molecular Science Program

Southern Illinois University

Carbondale, IL 62901

Project Manager:

Dan Banerjee, ICCI 

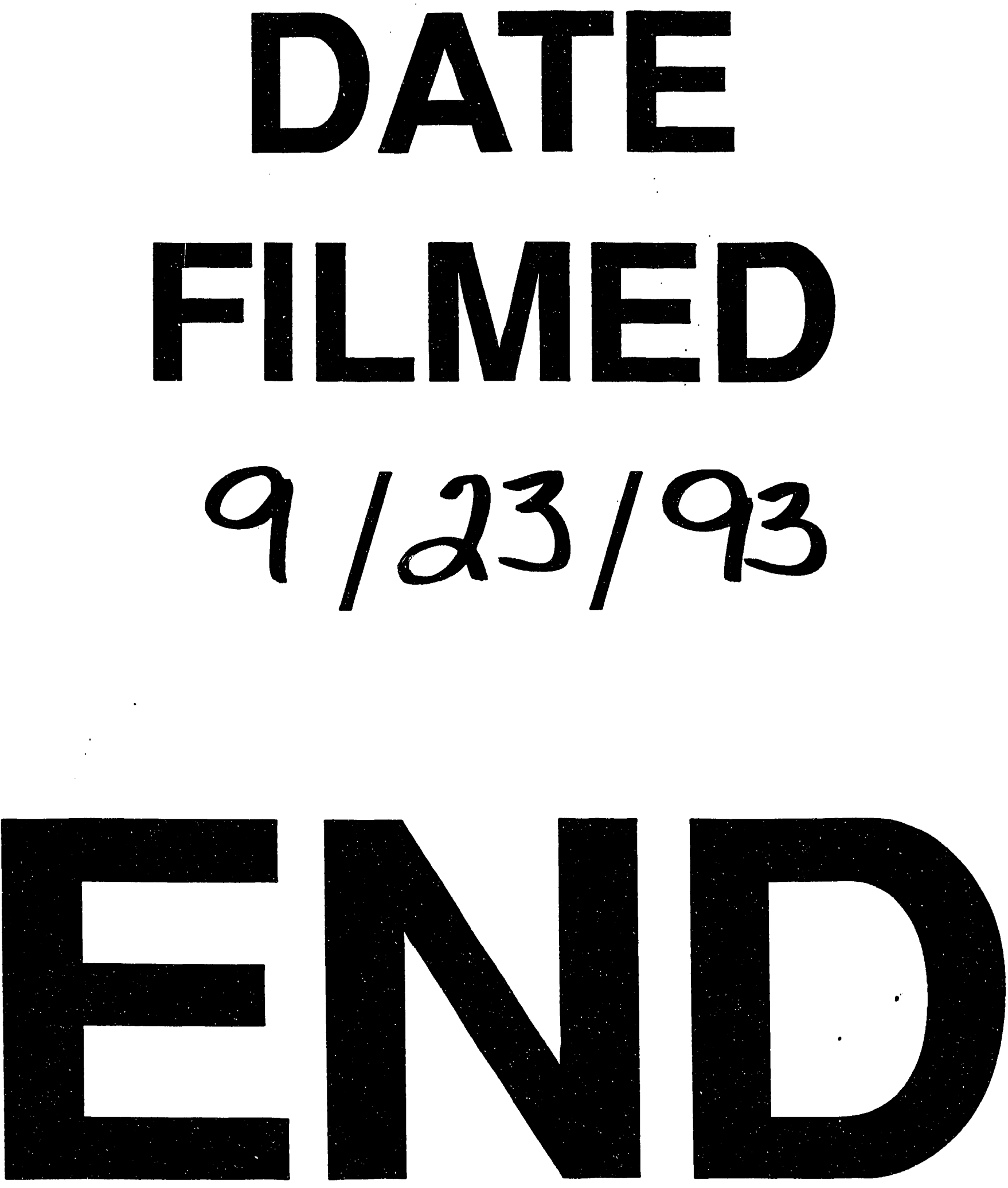
